\title{
Religious beliefs, coping skills and responsibility to family as factors protecting against deliberate self-harm
}

\author{
K Kannan, MB BS \\ Hospital Mesra Bukit Padang, Kota Kinabalu, Malaysia
}

S K Pillai, MB BS, MPM

J S Gill, MB BS, MPM

K O Hui, MB BS, MPM

Department of Psychological Medicine, University of Malaya Medical Centre, Kuala Lumpur, Malaysia

V Swami, PhD (Psychology)

Department of Public Health, University of Liverpool, Liverpool, UK

Background. Deliberate self-harm (DSH) ranges from behaviours aiming to communicate distress or relieve tension, but where suicide is not intended, to suicide. Not all individuals are prone to DSH, which suggests that there are factors that protect against it. Identifying these could play an important role in the management and prevention of DSH.

Objectives. This study examined whether religious beliefs, coping skills and responsibility to family serve as factors protecting against DSH in Kota Kinabalu, Sabah, Malaysia.

Method. A cross-sectional comparative study assessed DSH patients consecutively admitted or directly referred to Queen Elizabeth General Hospital and Hospital Mesra Bukit Padang during the period December 2006 - April 2007. DSH patients $(N=42)$ were matched with controls ( $N=42)$ for gender, age, religion, race, occupation and marital status. The DSH and control groups were compared using psychosocial tests that assess coping skills, religious beliefs and responsibility to family.

Results. There were significant differences in religious beliefs $(p=0.01)$ and responsibility to family $(p=0.03)$ between the DSH patients and the control group. There were also significant differences in coping skills, DSH patients tending to use emotion-orientated coping $(p=0.01)$ as opposed to taskand avoidance-orientated coping.

Conclusion. Consistent with international studies, coping skills (i.e. task-orientated skills), religious beliefs and responsibility to family were more evident in patients who did not attempt DSH than in those who did. These findings imply that treating DSH should not start only at the point of contact. Protective factors such as religious beliefs, responsibility to family and coping strategies can be inculcated from a very young age. However, caution is required in generalising the results owing to limitations of the study. Further extensive research on religious and psychotherapeutic interventions and prospective studies on protective factors will be helpful.

There is no widely accepted definition for suicide, even though it has been documented since time immemorial. The word is derived from the Latin for 'self-murder', and it is often a fatal act that represents the person's wish to die.' Few acts have such deep roots in social and human conditions, or such far-reaching consequences. ${ }^{2}$

Suicide is currently the 8th leading cause of death in the world and among the top 3 causes of death among 18 -24-year olds. ${ }^{3}$ It accounts for 1 - $2 \%$ of global mortality. In 1995 the annual world-wide incidence of successful suicide was 16/100 000 persons; this means that globally 1 in every 600 persons commits suicide every year.

Attempted suicide and deliberate self-harm (DSH) are terms used to describe acute self-infliction of physical harm or ingestion of poisonous substances that does not result in death. ${ }^{4}$

In Canada the rate of DSH has been estimated at around 304/100 000, ${ }^{5}$ and in the US National Institute of Mental Health's Epidemiological Catchment Area Study (1980 - 1985) it was found that $2.9 \%$ of respondents had made a suicide attempt. ${ }^{6}$ Maniam and Morris did a computerised search of the literature on suicidal behavior and ethnicity in Malaysia dating back to 1966, supplemented by other relevant published and research material. ${ }^{7}$ They found that the Indian population was over-represented among people who attempted suicide, with young women from the lower socio-economic groups being at particularly high risk. Forty-eight per cent of all individuals who had attempted suicide had used detergents or insecticides, pesticides or other agrochemicals. The authors commented on the easy availability and lethality of chemicals such as paraquat. 
Suicide and DSH are a tragic and potentially preventable public health problem, as both are conscious acts. Identifying protective factors could play a major role in their prevention and management. Maniam and Morris found very few studies of preventive approaches to $\mathrm{DSH}^{7}$, especially in our region. Studies on psychosocial factors contributing to DSH have been conducted in many states in peninsular Malaysia, but Sabah is in East Malaysia, where there are limited psychiatric resources. In view of this lack and the history and diverse ethnic background of the people of Sabah, we considered that a study of DSH in this region was indicated.

It has been hypothesised that religious beliefs, responsibility to family and coping skills help prevent suicidal behaviour. We therefore compared DSH and control groups using psychosocial tests to assess these characteristics. We defined DSH as intentional but not fatal self-poisoning or self-injury, irrespective of the apparent purpose of the act. ${ }^{8}$ DSH ranges from behaviours with no suicidal intent but aiming to communicate distress or relieve tension, to suicide. The term is preferred to 'attempted suicide' or 'parasuicide' because the motives or reasons for this behaviour include non-suicidal intentions.

\section{Methods}

The study was conducted in Kota Kinabalu, capital of Sabah, a Malaysian state located on the northern part of the island of Borneo. ${ }^{9}$ The official population estimate for the year 2006 was 2997 000. ${ }^{10}$ Hospital Mesra Bukit Padang la psychiatric hospitall and Queen Elizabeth General Hospital cater for the psychiatrically ill population of Kota Kinabalu.

The study was a cross-sectional comparative analysis of religious beliefs, coping skills and responsibility to family as factors protecting against DSH. The DSH patients were 42 consecutive male and female individuals aged $13-60$ years, consecutively admitted or directly referred to Queen Elizabeth General Hospital or Hospital Mesra Bukit Padang following an episode of DSH during the period December 2006 - April 2007. Inclusion criteria were ability to give written informed consent, availability of a consenting parent or legal guardian for those below 18 years or incompetent to give consent, ${ }^{11}$ and ability to read and write in English or Bahasa Malaysia.

The control group comprised 42 male and female patients aged 13 and over who were attending general outpatient clinics for minor medical illness (e.g. upper respiratory tract infection or dyspepsia, which would not warrant admission) without underlying chronic conditions. They were matched with the study group for age (standard deviation (SD) 2 years), gender, occupation, religion, race and marital status.

Ethical approval for the study was obtained from the hospital ethical committee under the authority of the Ministry of Health of Malaysia.

A series of psychosocial tests comprising the Coping Inventory in Stressful Situations (CISS), Reasons for Living Inventory (RLI), Hospital Anxiety and Depressive Scale (HADS) and Recent Life Events (RLS) questionnaire were administered to the DSH patients, after their condition had been stabilised, and the control group. The CISS is a 48-item questionnaire measuring 3 main domains of coping style, namely 'task-orientated coping', 'emotionorientated coping' and 'avoidance coping'. The resulting inventory was further factorised into 6 scales or reasons for living. The RLI consists of 6 domains, namely survival and coping beliefs, responsibility to family, child-related concerns, fear of suicide, fear of social disapproval, and moral objections. The HADS consists of 2 subscales, anxiety and depression, with 7 questions for each. The RLE questionnaire attempts to define negative life events over the last 12 months, and significantly whether the respondent thinks that they have a continuing influence.

The data collected were analysed using the SPSS (Statistical Package for the Social Sciences Version 11 .5) computer program. The $Q-Q$ plot test and Kolmogorov-Smirnov test were used to test the distribution of data, and the chi-square test and Mann-Whitney U-test to compare demographic data. An independent ttest was used to compare means between the DSH patients and the controls for quantitative variables that were tested to be normally distributed, while multiple logistic regression analysis was used to examine the significant relationship of multiple variables in the association between socio-demographic and psychological variables in DSH.

A pilot study conducted to test the reliability (test re-test) of the CISS and RLI found the Cronbach alpha values to be more than 0.7, indicating high internal consistency. The remaining questionnaires had already been validated locally and were therefore not used in the pilot study.

\section{Results}

\section{Demographic characteristics}

The mean age of the 42 DSH patients (cases) was 20.7 years and that for the control group 21.8 years. Most of the subjects 
(47.62\% of the DSH patients and $50 \%$ of the controls) were in the age group 21 - 30 years. The Mann-Whitney U-test showed these differences not to be significant (Z-score $-0.44, p=0.66$ ). Sociodemographic data for the cases and controls are set out in Table I. The variables were all dichotomised and analysed with the chisquare test to determine whether there was a significant difference between the two groups.

Approximately $66.7 \%$ of the respondents were of the Islamic faith, the other $33.3 \%$ being Christian. There was no significant difference between cases and controls with regard to gender or religion. Most of the subjects in both groups $161.9 \%$ of cases and $64.3 \%$ of controls) were single, separated or divorced. This difference was also not statistically significant $\left(\chi^{2}=0.05\right.$, $p=0.50)$. Similarly, there were no significant differences in distribution according to ethnic group or variables for education and occupation.

\section{Data on DSH}

The 42 DSH patients were interviewed about the events before, during and after the act. The findings are summarised in Table $\|$. Self-poisoning was the method of DSH most frequently used, and a trend towards using over-the-counter drugs was observed.

\section{Recent life events prior to DSH}

The most common life events over the past 6 months that had led to the DSH were related to marriage (34.9\%), family and social events $(25.9 \%)$ and courtship- and cohabitation-related events (Table III).

\section{Comparison of scores for religious beliefs and responsibility to family between case and controls}

Religious belief and responsibility to family in cases and controls were compared (Table IV). There was a significant difference between the two groups with regard to responsibility to family, child-related concerns and religious beliefs, the controls scoring significantly higher for all three categories.

\section{Comparison of coping skills between cases and controls}

Table V compares coping skills in the DSH patients and the control group. There were significant differences between the two groups, those who had not attempted DSH using more task-orientated coping $(t=4.31, p=0.00)$ and avoidance-based coping $(t=2.93$, $p=0.00)$. The avoidance-based coping methods most commonly

\begin{tabular}{|c|c|c|c|c|c|c|c|}
\hline & \multicolumn{2}{|c|}{ Group } & \multirow[b]{2}{*}{ Chi-square } & \multirow[b]{2}{*}{$p$-value } & \multirow[b]{2}{*}{ OR } & \multicolumn{2}{|c|}{$95 \% \mathrm{Cl}$} \\
\hline & $\begin{array}{c}\text { Controls } \\
N(\%)\end{array}$ & $\begin{array}{c}\text { DSH } \\
N(\%)\end{array}$ & & & & Upper & Lower \\
\hline \multicolumn{8}{|l|}{ Gender } \\
\hline Male & $3(7.1)$ & $3(7.1)$ & 0.00 & 0.66 & 1.00 & 0.19 & 5.26 \\
\hline Female & 39 (92.9) & $39(92.9)$ & & & & & \\
\hline \multicolumn{8}{|l|}{ Religion } \\
\hline Islam & $28(66.7)$ & $28(66.7)$ & 0.00 & 0.59 & 1.00 & 0.40 & 2.48 \\
\hline Christianity & $14(33.3)$ & $14(33.3)$ & & & & & \\
\hline \multicolumn{8}{|l|}{ Marital status } \\
\hline Single & $26(61.9)$ & 27 (64.3) & 0.05 & 0.50 & 0.90 & 0.37 & 2.19 \\
\hline Married & $16(38.1)$ & $15(35.8)$ & & & & & \\
\hline \multicolumn{8}{|l|}{ Education $^{\dagger}$} \\
\hline Low & 32 (76.2) & $34(80.9)$ & 0.28 & 0.40 & 0.75 & 0.26 & 2.15 \\
\hline High & $10(23.8)$ & $8(19.1)$ & & & & & \\
\hline \multicolumn{8}{|l|}{ Occupation ${ }^{\ddagger}$} \\
\hline Professional & $2(4.8)$ & $1(2.3)$ & 0.35 & 0.50 & 2.05 & 0.18 & 23.51 \\
\hline Non-professional & $40(95.2)$ & $41(97.6)$ & & & & & \\
\hline \multicolumn{8}{|l|}{ Age group } \\
\hline $13-20$ & $15(35.8)$ & $17(40.5)$ & 0.20 & 0.41 & 0.82 & 0.34 & 1.97 \\
\hline $21-40$ & $27(64.3)$ & $25(59.5)$ & & & & & \\
\hline $\begin{array}{l}p<0 \text { 05. There was no statisti } \\
\text { tLower education was defin } \\
\text { tNon-professionals were defi } \\
\mathrm{OR}=\text { odds ratio } \mathrm{Cl}=\text { confide }\end{array}$ & $\begin{array}{l}\text { een the contro } \\
\text { lary schooling } \\
\text { had a blue-co }\end{array}$ & $\begin{array}{l}\text { DSH indicating } \\
\text { her education }\end{array}$ & $\begin{array}{l}\text { nat the variables } \\
\text { s a diploma degr }\end{array}$ & $\begin{array}{l}\text { re controlled } t \\
\text { or higher quo }\end{array}$ & $\begin{array}{l}\text { e best } p \\
\text { ation. }\end{array}$ & & \\
\hline
\end{tabular}




\begin{tabular}{|c|c|c|}
\hline & $N$ & $\%$ \\
\hline \multicolumn{3}{|c|}{ Method most commonly used } \\
\hline Self-poisoning & 39 & 92.9 \\
\hline Self-injury & 2 & 4.8 \\
\hline Both & 1 & 2.3 \\
\hline \multicolumn{3}{|c|}{$\begin{array}{l}\text { How did they find out about the } \\
\text { method? }\end{array}$} \\
\hline Friend & 6 & 14.3 \\
\hline Don't know & 27 & 64.3 \\
\hline Media & 9 & 21.4 \\
\hline \multicolumn{3}{|c|}{$\begin{array}{l}\text { Would the method have killed } \\
\text { them? }\end{array}$} \\
\hline Yes & 19 & 45.2 \\
\hline No & 23 & 54.8 \\
\hline \multicolumn{3}{|l|}{ Previous episode? } \\
\hline One or more & 2 & 4.8 \\
\hline None & 40 & 95.2 \\
\hline \multicolumn{3}{|c|}{ Was the act planned? } \\
\hline Yes & 5 & 11.9 \\
\hline No & 37 & 88.1 \\
\hline \multicolumn{3}{|c|}{ Did they seek rescue? } \\
\hline Yes & 35 & 83.3 \\
\hline No & 7 & 16.7 \\
\hline \multicolumn{3}{|c|}{ Was there social support? } \\
\hline Yes & 39 & 92.9 \\
\hline No & 3 & 7.1 \\
\hline \multicolumn{3}{|l|}{ Support system } \\
\hline Family & 29 & 69.0 \\
\hline Friend & 10 & 23.8 \\
\hline None & 3.0 & 7.1 \\
\hline \multicolumn{3}{|c|}{$\begin{array}{l}\text { Alcohol/substance abuse or } \\
\text { dependence }\end{array}$} \\
\hline Yes & 1 & 2.4 \\
\hline No & 41 & 97.6 \\
\hline \multicolumn{3}{|c|}{ Any other medical illness } \\
\hline Yes & 5 & 11.9 \\
\hline No & 37 & 88.1 \\
\hline \multicolumn{3}{|c|}{ Past psychiatric illness } \\
\hline Yes & 1 & 2.4 \\
\hline No & 41 & 97.6 \\
\hline \multicolumn{3}{|c|}{$\begin{array}{l}\text { Contact with a doctor in past } \\
\text { month }\end{array}$} \\
\hline Yes & 11 & 26.2 \\
\hline No & 31 & 73.8 \\
\hline
\end{tabular}

used were social diversion $(p=0.01)$ and distraction $(p=0.01)$. Analysis showed that the DSH patients were more likely to use emotion-orientated coping ( $t=2.76, p=0.01)$.

\begin{tabular}{lcc} 
Table III. Recent stressful life events prior to DSH & \\
\hline Life events & $N$ & $\%$ \\
\hline Work & 0 & 0.00 \\
Education & 2 & 4.65 \\
Financial & 2 & 4.65 \\
Health & 2 & 4.65 \\
Bereavement & 0 & 0.00 \\
Migration & 2 & 4.65 \\
Courtship and cohabitation & 9 & 20.93 \\
Legal & 0 & 0.00 \\
Family and social & 11 & 25.58 \\
Marital & 15 & 34.88 \\
& $43^{*}$ & 100.00 \\
*One patient had two stressful life events. & & \\
\hline
\end{tabular}

\section{Family responsibility and religious beliefs compared with the HADS}

Family responsibility and religious belief were categorised into low (1 - 3) and high scores (4 - 6) based on the RLI, and these were then compared with the HADS. Analysis (Table VI) revealed that the DSH patients with less responsibility to their family had more symptoms of anxiety $(t=2.17, p=0.04)$ and depression $(t=3.04, p=0.03)$ than those with more responsibility. Similarly, DSH patients with less religious beliefs had more symptoms of anxiety $(t=3.04, p=0.00)$ and depression $(t=3.02, p=0.00)$ than those with more religious beliefs.

\section{Multivariate analysis}

Multiple logistic regression analysis was performed to investigate the relationship between the variables (Table VII). Task-orientated coping, emotion-orientated coping, fear of social disapproval and child-related concerns were found to have a p-value $<0.05$. Other $p$-values (for avoidance-orientated coping ( $p=0.65)$, distraction ( $p=0.53$ ), moral objection/religious belief ( $p=0.68$ ), etc.) did not approach significance. Each of the significant variables affects DSH individuals and is a substantial risk factor after taking into account the status of all the other variables tested, i.e. the significant variables can predict DSH. For example, having less child-related concerns poses an average of 1 point higher risk of DSH. The biggest limitation of this inventory is probably the lack of predictive validity.

\section{Discussion}

Religion is a philosophy and a way of life. It is said to define the person we are, how we view the world around us and how 


\begin{tabular}{|c|c|c|c|c|c|}
\hline & $N$ & Mean & SD & t-test & $p$-value \\
\hline \multicolumn{6}{|c|}{ Total responsibilty to family } \\
\hline Control & 42 & 5.20 & 0.77 & 2.28 & $0.03^{*}$ \\
\hline Case & 42 & 4.76 & 0.99 & & \\
\hline \multicolumn{6}{|c|}{ Total child-related concern } \\
\hline Control & 42 & 5.30 & 0.93 & 2.73 & $0.01^{*}$ \\
\hline Case & 42 & 4.63 & 1.28 & & \\
\hline \multicolumn{6}{|c|}{ Total fear of suicide } \\
\hline Control & 42 & 4.70 & 0.76 & 1.81 & 0.07 \\
\hline Case & 42 & 4.39 & 0.82 & & \\
\hline \multicolumn{6}{|c|}{ Total fear of social disapproval } \\
\hline Control & 42 & 5.02 & 1.01 & 1.31 & 0.19 \\
\hline Case & 42 & 4.69 & 1.25 & & \\
\hline \multicolumn{6}{|c|}{ Total religious belief } \\
\hline Control & 42 & 5.05 & 0.92 & 2.57 & $0.01^{*}$ \\
\hline Case & 42 & 4.46 & 1.18 & & \\
\hline$* p<005$ & & & & & \\
\hline
\end{tabular}

Table V. Comparison of coping skills between DSH patients and controls

\begin{tabular}{|c|c|c|c|c|c|}
\hline & $N$ & Mean & SD & t-test & p-value \\
\hline \multicolumn{6}{|c|}{ Task-orientated coping } \\
\hline Control & 42 & 68.02 & 8.24 & 4.31 & $0.00 *$ \\
\hline Case & 42 & 58.00 & 12.61 & & \\
\hline \multicolumn{6}{|c|}{ Emotion-orientated coping } \\
\hline Control & 42 & 51.38 & 9.02 & -2.76 & $0.01^{*}$ \\
\hline Case & 42 & 57.19 & 10.22 & & \\
\hline \multicolumn{6}{|c|}{ Avoidance-orientated coping } \\
\hline Control & 42 & 61.55 & 10.54 & 2.93 & $0.00^{*}$ \\
\hline Case & 42 & 52.90 & 15.92 & & \\
\hline \multicolumn{6}{|c|}{ Social diversion } \\
\hline Control & 42 & 20.07 & 3.22 & 2.52 & $0.01^{*}$ \\
\hline Case & 42 & 17.62 & 5.42 & & \\
\hline \multicolumn{6}{|l|}{ Distraction } \\
\hline Control & 42 & 30.31 & 6.08 & 2.70 & $0.01^{*}$ \\
\hline Case & 42 & 25.74 & 9.13 & & \\
\hline$p<005$ & & & & & \\
\hline
\end{tabular}

we interact with it. ${ }^{12}$ Only a small group of studies have been conducted in the area of religious beliefs and DSH, but findings indicate that beliefs do have a protective role. It is difficult to ascertain how religious a person is, but we can measure the belief system using questionnaires such as the RLI, which has domains on religious beliefs that measure perceived reasons for not committing suicide.
A study conducted in Kuala Lumpur, Malaysia, and assessing reasons for living in 40 individuals who had attempted suicide showed a significant relationship between hopelessness and suicidality. ${ }^{13}$ There were also significant differences between the ethnic groups studied, Indians scoring lower in most of the domains of the questionnaire than Malay and Chinese patients. ${ }^{13}$ Higher suicide and DSH rates noted in West Malaysia among the 


\begin{tabular}{|c|c|c|c|c|c|}
\hline & N & Mean & SD & $t$-test & p-value \\
\hline \multicolumn{6}{|l|}{ Group RF } \\
\hline \multicolumn{6}{|l|}{ Anxiety } \\
\hline Low (1 - 3) & 9 & 11.78 & 4.63 & 2.17 & $0.04^{*}$ \\
\hline High (4 - 6) & 33 & 8.55 & 3.77 & & \\
\hline \multicolumn{6}{|l|}{ Depression } \\
\hline Low (1 - 3) & 9 & 10.56 & 3.09 & 2.29 & $0.03^{*}$ \\
\hline High $(4-6)$ & 33 & 8.15 & 2.72 & & \\
\hline \multicolumn{6}{|l|}{ Group RB } \\
\hline \multicolumn{6}{|l|}{ Anxiety } \\
\hline Low (1 - 3) & 10 & 12.40 & 4.86 & 3.04 & $0.00 *$ \\
\hline High $(4-6)$ & 32 & 8.25 & 3.39 & & \\
\hline \multicolumn{6}{|l|}{ Depression } \\
\hline Low (1 - 3) & 10 & 10.90 & 3.25 & 3.02 & $0.00 *$ \\
\hline High (4 - 6) & 32 & 7.97 & 2.49 & & \\
\hline \multicolumn{6}{|c|}{$\begin{array}{l}* p<005 . \\
R F=\text { feelings of responsibility to family } R B=\text { religious beliefs. }\end{array}$} \\
\hline
\end{tabular}

Table VII. Association between coping skills, reasons for living and age*

\begin{tabular}{|c|c|c|c|c|c|c|c|c|}
\hline \multirow[b]{2}{*}{ Variable } & \multirow[b]{2}{*}{ B } & \multirow[b]{2}{*}{ SE } & \multirow[b]{2}{*}{ Wald } & \multirow[b]{2}{*}{ p-value } & \multirow[b]{2}{*}{$\operatorname{Exp}(B)$} & \multicolumn{2}{|c|}{$95 \% \mathrm{Cl}$ for $\operatorname{Exp}(\mathrm{B})$} & \multirow{2}{*}{$\begin{array}{c}\text { Nagelkerke } \\
\text { R-square }\end{array}$} \\
\hline & & & & & & Lower & Upper & \\
\hline Task coping & -0.18 & 0.05 & 11.95 & $0.00^{+}$ & 0.83 & 0.75 & 0.92 & 0.56 \\
\hline Emotion coping & 0.16 & 0.04 & 12.76 & $0.00^{\dagger}$ & 1.17 & 1.07 & 1.27 & \\
\hline Avoidance coping & 0.08 & 0.19 & 0.20 & 0.65 & 1.09 & 0.75 & 1.57 & \\
\hline Social avoidance coping & 0.04 & 0.27 & 0.02 & 0.88 & 1.04 & 0.62 & 1.76 & \\
\hline Distraction avoidance coping & -0.14 & 0.22 & 0.39 & 0.53 & 0.87 & 0.56 & 1.35 & \\
\hline Min. survival coping beliefs & -0.09 & 1.02 & 0.01 & 0.93 & 0.92 & 0.12 & 6.74 & \\
\hline Min. responsibility to family & -0.05 & 0.77 & 0.00 & 0.94 & 0.95 & 0.21 & 4.29 & \\
\hline Min. child-related concern & -1.00 & 0.48 & 4.30 & $0.04^{\dagger}$ & 0.37 & 0.14 & 0.95 & \\
\hline Min. fear of suicide & 0.26 & 0.73 & 0.13 & 0.72 & 1.30 & 0.31 & 5.45 & \\
\hline Min. fear of social disapproval & 0.37 & 0.39 & 0.93 & 0.33 & 1.45 & 0.68 & 3.11 & \\
\hline Min. religious reliefs & -0.20 & 0.48 & 0.17 & 0.68 & 0.82 & 0.32 & 2.10 & \\
\hline Age & 0.02 & 0.05 & 0.12 & 0.73 & 1.02 & 0.92 & 1.13 & \\
\hline Constant & 4.57 & 2.65 & 2.98 & 0.08 & 96.71 & & & \\
\hline
\end{tabular}

*There were significant differences between the two groups those who had not attempted DSH using more task-orientated coping ( $t=4.31 \quad p=0$ 00) and avoidance-based coping $(t=2.93 p=0.00)$. The avoidance-based coping methods most commonly used were social diversion $(p=0.01)$ and distraction ( $p=0$ 01). Analysis showed that the DSH patients were more likely to use emotion-orientated coping ( $t=-2.76 \mathrm{p}=0.01)$. The bold font indicates this. Task coping here would mean problem solving taking an initiative to find a solution to their stressors.

${ }^{\dagger} p<0.05$.

$B=$ positive or negative shows a positive or a negative correlation.

Indian minority led Maniam to postulate that Hinduism's view of suicide is more complex, as Hindu scriptures give conflicting views about whether suicide is permissible. ${ }^{14}$ This was further supported by Rao's experience in the field of suicidology in India. ${ }^{15}$

The present study was the first in Malaysia to compare religious beliefs between DSH attempters and non-attempters. The findings were similar to those of Malone et al., ${ }^{16}$ who reported that individuals with high depressive scores had less religious beliefs than individuals with lower depressive scores. We also showed that DSH attempters had fewer reasons for living and fewer religious beliefs compared with controls.

Some authors have investigated rates of suicide among various ethnic groups as a way of understanding its relationship to religion. Early and Akers found rates to be lower in blacks compared 
with whites, and suggested that an interactive role in black communities may protect them against DSH. ${ }^{17}$ In 2004 Dervic et al. analysed beliefs and religious affiliations of individuals who had attempted suicide, and found that compared with attempters, non-attempters endorsed significantly more reasons for living involving responsibility towards family, child-related concerns and religious beliefs (moral objections) to suicide, and more often reported a religious affiliation. ${ }^{18}$ Findings also show that religious belief protects against risk behaviour, including suicide attempts, in physically abused adolescents. ${ }^{19}$ Mallone et al. found that depressed patients who had not attempted suicide expressed more feelings of responsibility to family, more fear of social disapproval, stronger religious beliefs and moral objections to suicide, greater survival and coping skills and a greater fear of suicide than depressed patients who had attempted suicide. ${ }^{16}$

The following model provides one way to understand how religious belief protects one from DSH. Cornwall et al. ${ }^{20}$ identified 6 dimensions of religiosity laspects of religious activity, dedication and belief (religious doctrine)l, based on the understanding that there are at least 3 components to religious behaviour: knowing (cognition), feeling (affect), and doing (behaviour). In summary, religious doctrine forbids suicide (cognition) and results in less sadness (affect), which further results in less DSH (behaviour). This is an indirect or subconscious form of cognitive behaviour therapy used on oneself. Other reasons such as fatalism ${ }^{21}-$ a belief that one's life is predetermined by fate, placing one's life in external control - have also been suggested.

Tubergen et al. ${ }^{22}$ augmented Durkheim's social suicide theory in a useful way. Instead of relying on the Protestant-Catholic difference, they argued that two different explanations for the protective effect can be advanced. The first is that religious communities, or social networks in general, provide social and emotional support to their members, which prevents people from committing suicide. The second is that suicide is strongly prohibited by religious communities, and that religious communities go beyond that, protecting their members. ${ }^{22}$ Whatever explanations we come up with, the available data strongly suggest the protective value of religious belief. Religious belief could therefore play an important part in the management and prevention of suicide.

However, a potential limitation must be recognised when making conclusions regarding religious beliefs. We do not yet have a standardised measuring instrument to measure or compare religious beliefs that is widely accepted and free from criticism. Most measures mainly comprise questions assessing positive character traits or mental health. Spirituality, measured by indicators of good mental health, is therefore found to be correlated with good mental health. Such associations are meaningless and tautological. ${ }^{23}$

A possible limitation of our study is that two-thirds of our sample population was Muslim and the remainder Christian. To what extent the questions that were asked are applicable to either or both faiths cannot be known for certain.

A family consists of a domestic group of people lor a number of domestic groups), typically affiliated by birth or marriage, or by analogous or comparable relationships, which can include domestic partnership, cohabitation, adoption and surname. People joined by love and/or promises of commitment can also be regarded as a family. ${ }^{12}$ Commitment and interdependence are an integral part of this structure.

In order to determine the degree of responsibility to their family felt by respondents, statements such as 'It would hurt my family', 'My family depends on me' and 'I love and enjoy my family' were included in the RLI. We found that DSH attempters had fewer feelings of family responsibility than non-attempters. Even after DSH, however, the majority of the patients still felt they had some form of support system, and $69 \%$ of them said that the support came from their family. Earlier research suggests that individuals who receive support from family and friends are less likely to attempt suicide than those who do not. ${ }^{24}$ It is also interesting to note that family closeness strongly predicts absence of both ideation and attempts. Absence of a mother or father did not matter as long as there was closeness or an understanding relationship. ${ }^{25}$ Other studies have shown that communalism, family cohesion and family support were positively associated with each other. Higher levels of family cohesion and family support were associated with lower levels of suicidal ideation and depression. ${ }^{26}$ Interaction with family members, interdependence, effective communication and a caring and loving relationship are how harmonious relationships are built. Deviation from this norm leads to a dysfunctional family and decreases the threshold for DSH. A sense of connectedness to family emerged as a factor protecting against DSH that cut across gender and ethnic groups of adolescents. ${ }^{27}$ A protective effect of family connectedness and cohesion was also noted among American Indian and Alaskan youth, ${ }^{26}$ a sense of responsibility and commitment to their family preventing an individual from attempting DSH.

In the context of the present study, Rosnah and Halim${ }^{28}$ in interviews with urban and rural members of the Kadazan-Dusun ethnic group in Sabah found significantly less interaction among 
the urban Kadazan-Dusuns compared with the rural folk. They attributed this disruption of the normal close relationship and family cohesiveness to urbanisation and rural-urban migration. This would explain why there are higher rates of DSH in the urban population.

Coping is defined as the process of managing taxing circumstances, making an effort to solve personal and interpersonal problems, and seeking to master, minimise, reduce or tolerate stress and conflicts. ${ }^{12}$ Sound coping and problem-solving skills are important in facing day-to-day adversities. Most of the literature on coping argues that there should be a distinction between emotion-orientated coping (person-orientated coping) and taskorientated coping (problem-focused coping). A third category, avoidance, can include both task- and emotion-orientated strategies (distraction avoids stressors by engaging in a substitute task, while social diversion avoids stressful situations by seeking help from others). ${ }^{29}$ In general, task-orientated coping skills are positively, and emotion-orientated coping negatively, related to good adaptation and mental health, ${ }^{30}$ while emotion- or personorientated coping is a primitive form of coping strategy; a person will tend to blame him- or herself, be preoccupied with aches, worry, become tense, etc. This resembles immature defence mechanisms such as hypochondriasis and somatisation used by some psychiatric patients.

Our study showed that subjects who attempted DSH used more emotion-orientated coping and less task-and avoidance-orientated coping compared with controls. In confronting stressful life events, DSH patients are more likely to use emotional discharge than task-orientated means. These findings support those of Azhar, who also found that task-orientated coping appeared to be used less among subjects who had committed acts of DSH than among control subjects. The DSH subjects also tended to use emotionorientated ways of coping with stressful situations. ${ }^{31}$ Endler and Parker found a strongly positive relationship between emotionorientated coping and both psychiatric symptomatology and depression. ${ }^{32}$

Compared with individuals having thoughts about suicide and those making a first attempt, people making a repeat attempt have been found to score significantly lower on problem-solving confidence (Rudd et al. ${ }^{33}$ ). Part of emotion-orientated coping can involve blaming oneself for getting into distressing situations and for other distressing events. Marusic and Goodwin ${ }^{34}$ found similar coping patterns in patients with suicidal ideation, DSH and physical pain. They noted that suicidal ideation and DSH are associated with distinct coping styles among patients with physical illnesses, and specifically that maladaptive lavoidant and emotional) rather than adaptive (rational and detachment) coping styles were associated with an increased risk of thoughts of specific types of self-harm. ${ }^{34}$

It can be hypothesised that individuals resort to emotion-orientated coping because of life events, environment and past experiences, and/or a personality that predisposes them to this style. It has also been suggested that suicidal subjects fail to de-emphasise the importance of a perceived problem or source of stress, and that they lack the ability to obtain new information required to resolve stressful life events. ${ }^{35}$ Insight into coping skills used by DSH patients plays an important role in prevention and management of these acts, and programmes introducing problem solving or taskorientated coping could protect against subsequent attempts.

\section{Conclusions and recommendations}

Within 1 year of a DSH attempt, $15-16 \%$ of individuals will make a repeat attempt and $0.5-2.4 \%$ will commit suicide. Suicides within a year of DSH amount to a quarter of all suicides in the UK. ${ }^{36}$ These figures are alarming and highlight the importance of suicide prevention and management strategies.

Our findings are consistent with previous international studies on factors protecting against suicide. In summary, we found that individuals who attempted DSH had fewer feelings of family responsibility and less religious beliefs, and that in general this group used emotion-orientated coping skills when faced with stressors, as opposed to task-orientated and avoidant forms of coping. Other important findings were the influence of media and friends in the method chosen for DSH. A trend towards using over-the-counter drugs as a mode of self-poisoning was also observed.

An important implication of the study is the recognition that treating DSH does not start at the point of contact with medical services. Protective factors such as religious beliefs, responsibility to family and coping strategies can be inculcated from a very young age. The complex process by which early experiences predispose to self-harm as a response to stress may be understood in terms of attachment theory. ${ }^{37}$ As a form of primary prevention, educational systems should not emphasise academic achievement alone as their primary goal. The aim should be to produce an individual who is both intelligent and resilient to face adversities, so the school curriculum should also emphasise problem-solving skills, coping strategies and moral values. The latter would focus on family cohesion and religious beliefs. 
The study also highlights the importance of problem-solving and coping strategies in the treatment of DSH patients, and indicates that involving the family by means of multi-systemic therapy would be beneficial. This system combines 3 basic approaches: teaching parenting skills (if needed), strengthening family relationships, connectedness and emotional cohesion within the family, and enhancing family problem-solving skills. ${ }^{27}$

This and other studies show that religious affiliation has a role in protecting against DSH, and including this in psychotherapeutic interventions when appropriate could help prevent subsequent DSH attempts. In Sabah and Malaysia, leaders of the different religions could complement the role of medical professionals through their network of services. However, as mentioned earlier, it is possible that the issue of religious belief may be a major limitation owing to disagreement on how to measure it, especially in a multi-ethnic population with different religions like Malaysia. Another problem is that while religious beliefs can be a source of comfort, hope and meaning, they can often be entangled with psychiatric disorders, making it difficult to determine whether they are a resource or a liability. ${ }^{38}$ In trying to create an inclusive measure of spirituality and religiousness that would be acceptable worldwide, one also runs the risk of being too broad and losing the core meaning of the words. ${ }^{39}$

Caution is required when generalising the study results, as the study sample was small and there were other limitations such as recall errors, Hawthorne effect, and selection of cases and site of study. It is recommended that the study be repeated on a larger scale, including the community and both public and private hospitals. Further research on religious psychotherapeutic interventions and prospective studies on protective factors would be of great value.

\section{References}

1. Saddock BJ, Saddock VA, eds. Kaplan \& Sadock's Synopsis of Psychiatry. 9th ed. Philadelphia: Lippincott Williams \& Wilkins, 2003

2. Retterstol N. Suicide - a European Perspective. Cambridge: Cambridge University Press, 1993

3. World Health Organization (1998). Primary Prevention of Mental Disorders, Neurological \& Psychosocial Disorders. Geneva: WHO, 2001

4. Kerkhof AJM, Arensman E. Attempted suicide and deliberate self harm: Epidemiology and risk factors. Gelder MG, Juan J. López-lbor لl, Andreasen N, eds. Oxford Textbook of Psychiatry. New York: Oxford University Press, 2000.

5. Sakinofsky I. The epidemiology of suicide in Canada. In: Leenaars AA, Wenckstern S, Sakinofsky I, Dyck RJ, Kral MJ, Bland RC, eds. Suicide in Canada. Toronto: University of Toronto Press, 1996

6. Moscicki EK. O'Carroll P, Rae DS, et al. Suicide attempts in Epidemiological Catchment Area Study. YaleJ Biol Med 1988;61:259-268.

7. Maniam T, Morris P. Ethnicty and suicidal behavior in Malaysia: A review of the literature. Transcult Psychiatry 2001;38(1):51-61.

8. Hawton K, Catalan J. Attempted Suicide, a Practical Guide to Nature and Management. Oxford: Oxford University Press, 1987
9. Sabah's Heritage: A Brief Introduction to Sabah's History. Kota Kinabalu, Sabah: Muzium Publications, 1992

10. Monthly Statistical Bulletin Sabah. Sabah, Malaysia: Department of Statistics, 2007

11. The Nuremberg Code (1947). In: Mitscherlich A, Mielke F. Doctors of Infamy: the Story of the Nazi Medical Crimes. New York: Schuman, 1949: xxiii-xxv.

12. Wikipedia. Definitions for coping, religion and family. Wikipedia.org laccessed 1 July 2008).

13. Koh OH, Zuraida NZ, Low CC, Jesieet SG. Reasons for staying alive in suicide attempters across different ethnic groups admitted to UUMC. Malaysian Journal of Psychiatry 2002; 10(2):40-44.

14. Maniam T. Why do Malaysian Asian Indians have high suicide rates? In: Vijayakumar L, ed. Suicide Prevention: Meeting the Challenge Together. Chennai: Orient Longman Private Ltd, 2003:199-213.

15. Rao V. Religious, cultural and philosophical perspectives of suicide in India. In: Vijayakumar L, ed. Suicide Prevention: Meeting the Challenge Together. Chennai Orient Longman Private Ltd, 169-177.

16. Malone KM, Oquendo MA, Haas GL, Ellis SP, Li S, Mann JJ. Protective factors against suicidal acts in major depression: reasons for living. Am J Psychiatry 2000; 157: 1084-1088.

17. Early KE, Akers RL. 'It's a white thing': an exploration of beliefs about suicide in the African-American community. Deviant Behavior: An Interdisciplinary Journal 1993; 14:277-296.

18. Dervic K, Oquendo MA, Grunebaum MF, Ellis S, Burke AK, Mann لע. Religious affiliation and suicide attempt. Am J Psychiatry 2004;161:2303-2308.

19. Perkins DF, Jones KR. Risk behaviors and resiliency within physically abused adolescents. Child Abuse Neglect 2004;28:547-563.

20. Cornwall M, Albrecht SL, Cunningham PH, Pitcher BL. The dimensions of religiosity: A conceptual model with an empirical test. Review of Religious Research 1986;27:226-244.

21. Hovey JD, King CA. Suicidality among acculturating Mexican Americans: Current knowledge and directions for research. Suicide Life Threat Behav 1997;27:92-103

22. Tubergen VF, Grontenhuis TM, Ultee W. Denomination, religious context, and suicide: Neo-Durkheimian multilevel explanations tested with individual and context data. J Sociol 2005; 111 :797-823.

23. Koenig HG. Concerns about measuring 'spirituality' in research. J Nerv Ment Dis 2005; 196(5):349-355.

24. Garlow SJ, Purselle D, Heninger M. Ethnic differences in patterns of suicide across the life cycle. Am J Psychiatry 2005; 162:319-323.

25. O'Donnell L, O'Donnell C, Wardlaw DM. Risk and resiliency factors influencing suicidality among urban African-American and Latino youth. Am J Community Psychol 2004;33(1-2):37

26. Lewis TH, Molock SD. Cultural orientation, family cohesion, and family support in suicide ideation and depression among African American college students. Suicide Life Threat Behav 2000;30(4):34 1-353.

27. Borowsky WI, Ireland M, Resnick MD. Adolescent suicide attempts: Risks and protective factors. Pediatrics 2001; 107(3):485-493.

28. Rosnah I, Halim AO. Kualiti Keluarga Kadazan-Dusun: Satu wawancara kumpulan berfokus. Convocation University Malaysia Sabah. Affluent Master Sdn. Bhd, 1999.

29. Endler NS, Parker JDA. Development of CISS. Coping Inventory for Stressful Situations Manual. Toronto: Multi-health System Inc., 1990:29-37.

30. Compas BE, Malcarbne VL, Fondacaro KM. Coping with stressful events in older children and young adolescents. J Consult Clin Psychol 1988;56:405-41 1.

31. Azha, S. Coping styles and social support networks among patients admitted for DSH. A case control study. MMed (Psychiatry) dissertation, University Kebangsaan Malaysia, 2005.

32. Endler NS, Parker JDA. Assessment of multidimensional coping: Task, emotion, and avoidance strategies. Psychol Assess 1994;6:50-60

33. Rudd MD, Joiner T, Rajab MH. Relationship among suicide ideators, attempters and multiple attempters in a young adult sample. J Abnorm Psychol 1996; 105:541-550.

34. Marusic A, Goodwin RD. Suicidal and deliberate self-harm ideation among patients with physical illness: The role of coping styles. Suicide Life Threat Behav 2006;36(3):323-328.

35. Horesh N, Rolnic T, lancu I, et al. Coping styles and suicide risk. Acta Psychiatr Scand 1996;93:489-493.

36. Horrocks J, House A. Self poisoning and self injury in adults. Clin Med 2002;2:509512.

37. Keeley HS, O'Sullivan M, Corcorn P. Background stressors and deliberate self-harm. Psychiatric Bulletin 2003;27:41 1-415

38. Koenig HG. Research on religion, spirituality, and mental health: a review. Can J Psychiatry 2009;54(5):283-291

39. Moreira-Almeida A, Koenig HG. Retaining the meaning of the words religiousness and spirituality: a commentary on the WHOQOL SRPB group's 'A cross-cultural study of spirituality, religion, and personal beliefs as components of quality of life'. Soc Sci Med 2005;62(6): 1486-1497 